\title{
Surface Roughness and Hydrophilicity of Titanium after Anodic Oxidation
}

\author{
Li Baoe1, Li Jun1, Liang Chunyong1, Li Haipeng1, Guo Litong ${ }^{2}, \quad$ Liu Shimin ${ }^{3}$, \\ Wang Hongshui ${ }^{1}$
}

${ }^{1}$ Hebei University of Technology, Tianjin 300130, China; ${ }^{2}$ China University of Mining and Technology, Xuzhou 221116, China; ${ }^{3}$ Tianjin University of Commerce, Tianjin 300134, China

\begin{abstract}
Anodic oxidation was applied to prepare the nanostructured titanium surface with different roughnesses and hydrophilicities. The morphology was characterized by scanning electron microscopy (SEM). The surface roughness was tested by atomic force microscopy (AFM), and the hydrophilicity was assessed from the contact angle between the deionized water and sample surface at room temperature. The results show that surface morphologies change remarkably with applied voltage and oxidation time during anodic oxidation. Under optimized oxidation conditions, well-ordered nanotube arrays were fabricated on the Ti surface. Roughness values increase with increase of the oxidation time, ranging from several dozen to several hundred nanometers, while the influence of voltage on surface roughness is not obvious. The hydrophilicity increases initially with the increase of oxidation time, but then decrease. The variations of surface morphology, roughness and hydrophilicity are correlated to the reactions occurring during the anodic oxidation.
\end{abstract}

Key words: titanium; anodic oxidation; roughness; hydrophilicity

Titanium and its alloys are widely applied as implant materials in many medical fields including dentistry and orthopedics due to their excellent mechanical properties, high corrosion resistance and good biocompatibility ${ }^{[1,2]}$. It was reported that these favorable properties resulted from the chemical stability and the structure of the titania $\left(\mathrm{TiO}_{2}\right)$ film which grew spontaneously on the surfaces of $\mathrm{Ti}$ and its alloys upon exposure to air. However the $\mathrm{TiO}_{2}$ film is bioinert, which usually leads to the insufficient ossointegration ${ }^{[3,4]}$. Therefore, the surface modification of Ti and its alloys is required to enhance their bioactivity.

A number of methods (e.g., sand blasting, acid etching, hydroxyapatite coating) have been employed to modify the Ti implant surfaces. However, a major disadvantage of these approaches is that they are either incapable of producing highly controllable surface structure, or prone to impose toxicity on the cells/tissues due to the harmful chemical residuals on the implant surface. Anodic oxidation is a low-cost, efficient, versatile technique to produce oxide coatings with highly controllable nanostructures. The anodic oxidized coatings usually have strong interfacial adhesion due to their direct in-situ growth on metal substrates, and the discharging-associated thermal effect also makes the coating rigid. During recent years, $\mathrm{TiO}_{2}$ coatings with controllable nanostructures have been produced on $\mathrm{Ti}$ surface by anodic oxidation and proved to have good bioactivity ${ }^{[5]}$. Therefore, the anodized $\mathrm{TiO}_{2}$ coatings have great potential as bioimplant materials in clinic.

The nanostructure of the oxidized $\mathrm{TiO}_{2}$ coatings has been

Foundation item: National Natural Science Foundation of China $(51201056,51401146,81100789)$; Natural Science Foundation of Hebei Province of China (E2013202021, E2013202022); Science and Technology Plan Project of Hebei Province (13211027); Science and Technology Correspondent Project of Tianjin (14JCTPJC00496)

Corresponding author: Li Haipeng, Ph. D., Professor, School of Materials Science and Engineering, Hebei University of Technology, Tianjin 300130, P. R. China, Tel: 0086-22-60204129, E-mail: lhpcx@163.com 
proved to play a critical role in improving the bioactivity. However, till now, the mechanism of the beneficial effect of nanostructures on bioactivity is not well understood, and there is still no consensus on the optimal nanostructures for the biomedical application ${ }^{[6]}$. The bioactivity of biomaterials are known to strongly depend on their surface properties, especially surface roughness and hydrophilicity, which are two important factors regulating a number of biological events including protein adsorption, cell attachment and other aspects of cell behaviors including proliferation and differentiation ${ }^{[7]}$. Therefore, the investigation of the influence of surface nanostructures on the surface roughness and hydrophilicity will definitely help understanding how the surface nanostructures affect the bioactivity, thus, providing more insight into the design of the optimal surface on the implant surface.

In the present paper, to conduct the systematic research on the relationship between roughness, hydrophilicity and the anode oxidation induced nanostructures, $\mathrm{TiO}_{2}$ coatings with different types of nanostructures were prepared by adjusting anode oxidation conditions (e.g. voltage and oxidation time), and the influence of nanostructures on surface roughness and hydrophilicity was also investigated.

\section{Experiment}

Commercially pure $\mathrm{Ti}$ plates with dimension of $10 \mathrm{~mm} \times 10$ $\mathrm{mm} \times 1 \mathrm{~mm}$ were mechanically polished by $1000 \#$ abrasive paper, and then ultrasonically cleaned successively in acetone, ethanol and deionized water. Anodic oxidation was carried out in potentiostatic mode at room temperature using a direct current (DC) voltage source (WYK-150, Yangzhou, China) in $1.0 \mathrm{~mol} / \mathrm{L}$ $\mathrm{NaF}$ electrolyte. The Ti plate was used as anodic electrode, and rectangular graphite was used as cathode electrode. The distance between anodic and cathodic electrodes was about $40 \mathrm{~mm}$. After anodic oxidation, all samples were ultrasonically cleaned with deionized water, and then air-dried. Samples without anodic oxidation were used as the control group.

The surface morphologies of samples were observed using scanning electron microscope (SEM, HITACHI S-4800). The surface roughness was characterized by atomic force microscope (AFM, Agilent 5500). The hydrophilicity was assessed from the measurements of the contact angle between the deionized water and sample surface at room temperature. Drop volumes of $2 \mu \mathrm{L}$ were chosen to avoid gravitation-induced shape alteration and to diminish the evaporation effects. The drop image was acquired using a digital camera $(1280 \times 960$ pixels $)$ attached to a microscope and processed by an image analysis software.

Samples were prepared in quintuplicate for each group. Standard deviations were plotted as error bars for the data points on all figures. Statistical difference was determined by Students t-test. Difference with $p<0.05$ was considered to be significant.

\section{Results}

\subsection{Surface morphologies of anodized Ti}

Fig.1 shows surface morphologies of the Ti samples treated by anodic oxidation at $10 \mathrm{~V}$ for $10 \mathrm{~min}, 30 \mathrm{~min}, 1 \mathrm{~h}$ and $4 \mathrm{~h}$. From these surface images, it can be seen, when Ti samples are anodic oxidized at $10 \mathrm{~V}$ for $10 \mathrm{~min}$, nanopores and nanotube arrays with diameters of $20 \sim 30 \mathrm{~nm}$ are obtained on the surface (Fig.1a). The diameters of nanopores and the nanotube arrays increase with the increasing of oxidation time (Fig.1b). When the oxidation time is $1 \mathrm{~h}$, only nanotubes with inner diameters of 40 50 $\mathrm{nm}$ are formed, and uniformly distributed over the entire surface (Fig.1c). However, as the oxidation time is further prolonged to $4 \mathrm{~h}$, the surface structure and the diameters of nanotubes remain unchanged (Fig.1d).

Upon increasing the voltage from $10 \mathrm{~V}$ to $20 \mathrm{~V}$, the surface morphologies of the Ti samples treated for different time are shown in Fig.2. It can be seen that after anodic oxidation for 10 and $30 \mathrm{~min}$, only nanopores are obtained and uniformly distributed over the entire surface on $\mathrm{Ti}$ substrate (Fig.2a), which is different from the case at a voltage of $10 \mathrm{~V}$ where both nanopores and nanotubes are formed simultaneously (Fig.1a, Fig.1b). The diameters of nanopores also increase with the increase of oxidation time (Fig.2b), which is in good agreement with the results shown in Fig.1. When the Ti samples are treated for $1 \mathrm{~h}$, some nanotubes and collapsed structure are observed on the $\mathrm{Ti}$ surfaces (Fig.2c). As the oxidation time is further prolonged to $4 \mathrm{~h}$, mainly collapsed structure is distributed over the entire surface. In addition, the diameter of nanostructures of samples treated at $20 \mathrm{~V}$ is much larger than that treated at $10 \mathrm{~V}$ (Fig.2d)
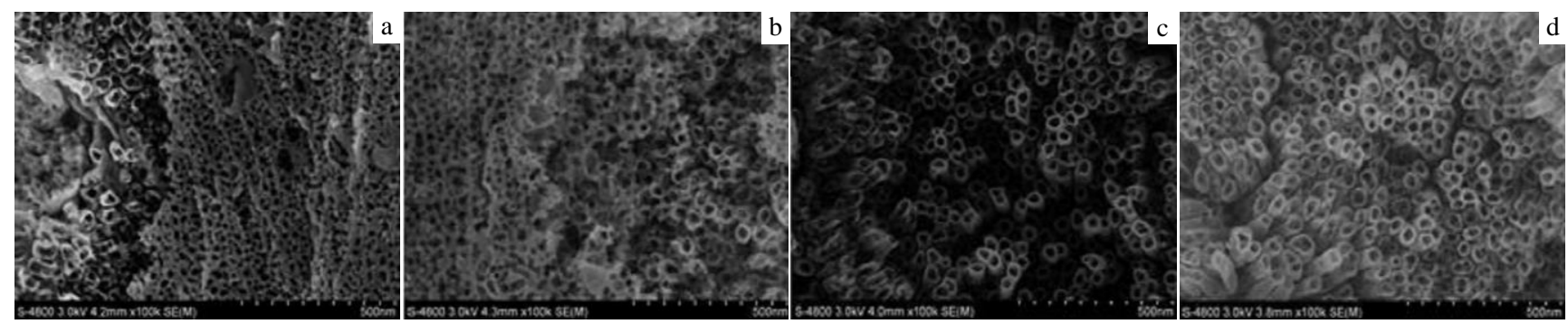

Fig.1 Surface morphologies of the Ti samples treated by anodic oxidation at $10 \mathrm{~V}$ for $10 \mathrm{~min}(\mathrm{a}), 30 \mathrm{~min}(\mathrm{~b}), 1 \mathrm{~h} \mathrm{(c)}$, and $4 \mathrm{~h}(\mathrm{~d})$ 

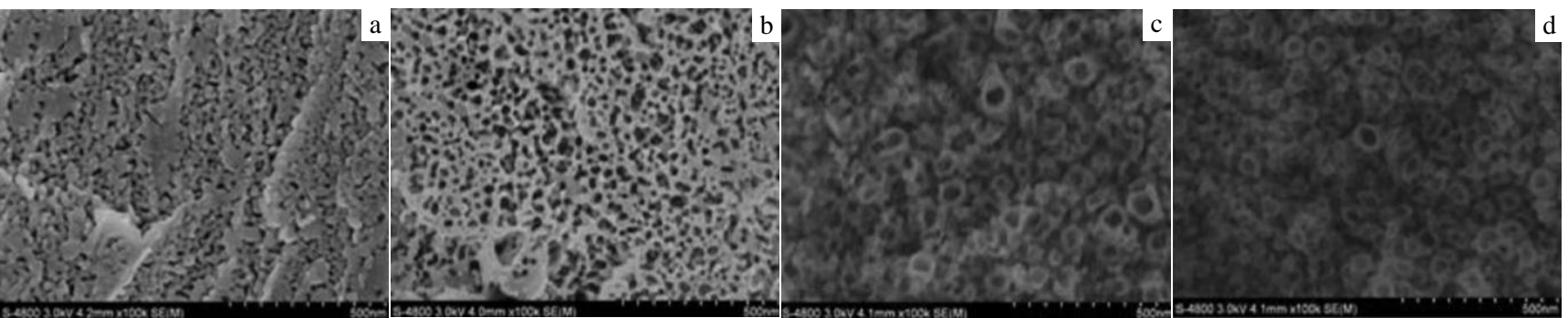

Fig.2 Surface morphologies of Ti samples treated by anodic oxidation at $20 \mathrm{~V}$ for $10 \mathrm{~min}(\mathrm{a}), 30 \mathrm{~min}(\mathrm{~b}), 1 \mathrm{~h} \mathrm{(c),} \mathrm{and} 4 \mathrm{~h}$ (d)

Fig.3 shows surface morphologies of the Ti samples treated at $30 \mathrm{~V}$ for different time. When the Ti samples are treated at $30 \mathrm{~V}$ for short time (10 and $30 \mathrm{~min}$ ), nanopores are observed, and the size of nanopores treated for $30 \mathrm{~min}$ is much larger than that treated for $10 \mathrm{~min}$ (Fig.3a and 3b). When the oxidation time is increased to $1 \mathrm{~h}$, nanotubes with some collapsed structure are observed (Fig.3c). And the nanotubes disappear from the surface of samples treated for 4 h (Fig.3d).

\subsection{Surface roughness of anodized $\mathrm{Ti}$}

Fig.4 shows the surface roughnesses of the Ti samples after anodic oxidation for different time. It can be seen that roughness values increase with the increase of oxidation time, ranging from several dozen to several hundred nanometers. When samples are initially oxidized, the surface roughness is increased quickly; however, as the oxidation time is further prolonged, the growth rate of roughness values is reduced. While the influence of voltage on the surface roughness is not obvious (results are not shown here).

\subsection{Surface hydrophilicity of anodized Ti}

The contact angles between the anodic-oxidized samples and deionized water are represented in Fig.5. From this figure, it can be see that the contact angle of water on the Ti surface without anodic oxidation is about $89.5^{\circ}$. After anodic oxidation for $5 \mathrm{~min}$, the contact angle of water is increased, indicating that the sample surface is converted to a hydrophobic state. When the oxidation time is further prolonged to $30 \mathrm{~min}$, the contact angle of water is decreased to less than $90^{\circ}$, meaning that sample surface is converted to a hydrophilic state again. This phenomenon was also seen in other studies ${ }^{[8]}$. From then on, the contact angles of water

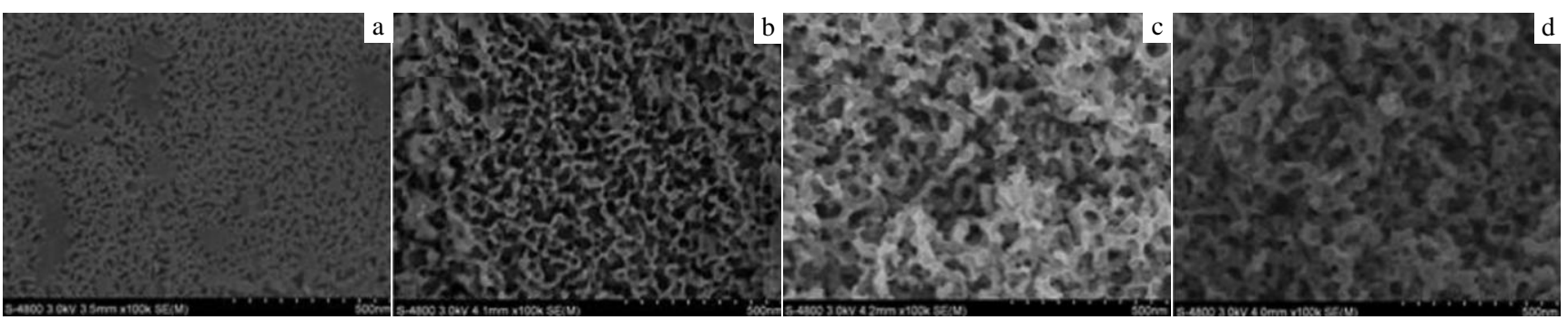

Fig.3 Surface morphologies of the Ti samples treated by anodic oxidation at $30 \mathrm{~V}$ for $10 \mathrm{~min}(\mathrm{a}), 30 \mathrm{~min}(\mathrm{~b}), 1 \mathrm{~h} \mathrm{(c),} \mathrm{and} 4 \mathrm{~h}$ (d)

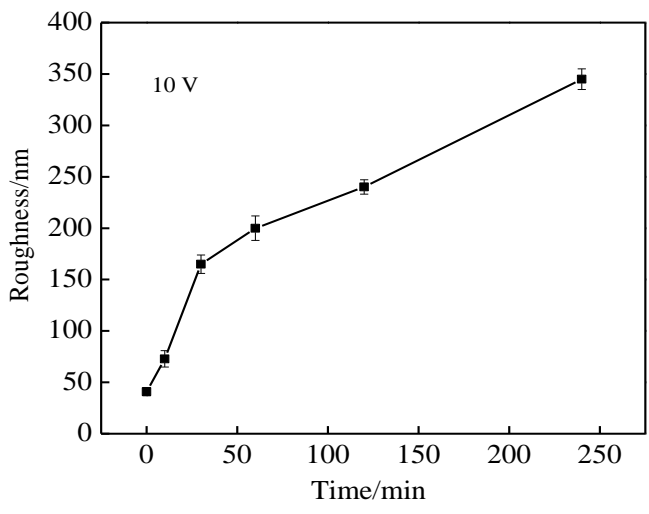

Fig.4 Surface roughnesses of Ti samples after anodic oxidation

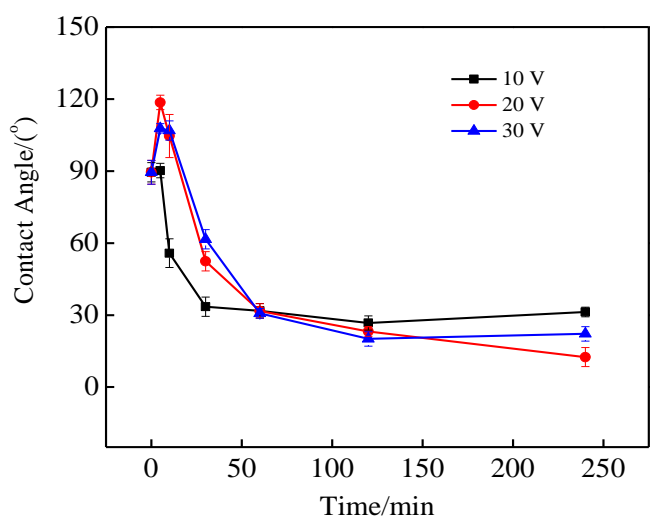

Fig.5 Water contact angles of Ti samples after anodic oxidation 


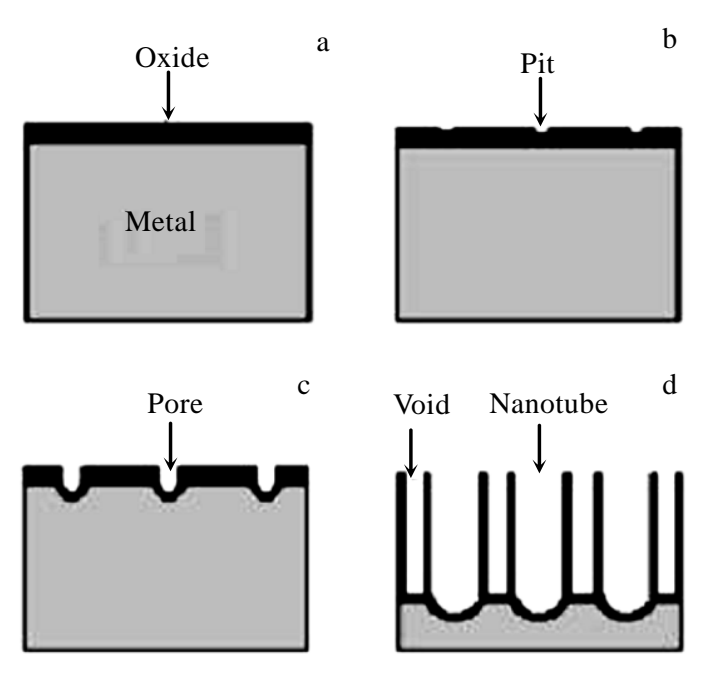

Fig.6 Schematic diagram of the formation of nanostructures on Ti surface by anodic oxidation

decrease with the increasing of oxidation time, and then remain stable when oxidation time is prolonged to a certain extent. Anodized under different voltages, the similar variation trend of hydrophilicity was observed, however, the statistical significance among different voltages was not obvious.

\section{Discussion}

The formation of nanotubular $\mathrm{TiO}_{2}$ coating during anodic oxidation could be described as follows: during the process of anodic oxidation, $\mathrm{Ti}$ reacts with oxygen (from $\mathrm{H}_{2} \mathrm{O}$ ) to form an oxide layer, as shown in Fig.6a. Due to the formation of the oxide layer, the electric field intensity in the layer increases sharply, and then the consequent oxide growth occurs. However, as the system is under a constant voltage, the electric field within the oxide layer is progressively reduced by the increasing of oxide growth, so the oxidation process is self-limiting ${ }^{[9,10]}$. The field strength would slack down the binding force of Ti-O bond, which makes the $\mathrm{Ti}^{4+}$ ions that have combined with $\mathrm{O}^{2-}$ combine with $\mathrm{F}^{-}$ions (from the electrolyte), resulting in the formation of soluble fluoride complexes ${ }^{[11]}$. This process is called field-assisted dissolution, and at this stage the oxide layer partially dissolved to form pits, as shown in Fig.6b. The above described dissolution will continue, and then it makes the pits into pores, as shown in Fig.6c. As the oxidation time is prolonged, pore size is expanded and deepened. The thickness of the oxide film is thicker at the wall than at the bottom; consequently, the electrical field intensity at the pore bottom is much higher than that at the wall. Therefore, $\mathrm{TiO}_{2}$ will be consumed at higher rate near the bottom of the pores, which results in further pore growth towards the vertical direction on the Ti substrate, and finally a tubular structure is yielded, as shown in Fig.6d.

Many parameters can affect the nanostructures of $\mathrm{TiO}_{2}$ coating during anodic oxidation process, such as voltage, current, oxidation time, and temperature of the solution. Among them, voltage and oxidation time are the two most important factors. In the present research, the two parameters have been investigated in detail. At low voltages of $10 \mathrm{~V}$, electric current is small, and heat emission is low, so the influence of solution temperature on the Ti surface is not obvious. It was reported that the small current would lead to the growth of nanotubes with long length, and the low voltage and solution temperature are mainly attributed to the diameters ${ }^{[8,9,12]}$. So, when voltage is low, the expanding effect of nanopores is weak initially, while the growth of nanotubes is dominant, so that nanotubes together with nanopores can be observed for $10 \mathrm{~V}$ in the early stage, but could hardly be observed at higher voltage (e.g. 20 and $30 \mathrm{~V}$ ). However, as oxidation time is prolonged, the influence of expanding and deepening effects of nanopores are more and more obvious, resulting in the formation of only nanotubes. That is also the reason that the diameter of nanostructures treated for long time or at high voltages is much bigger than that treated at $10 \mathrm{~V}$ for short time. However, higher voltage could produce higher heat emission that increase the solution temperature, and the high solution temperature would damage the formation of nanotubes and lead to the collapse of nanostructures, that is why a lot of collapsed structure can be seen on the sample surface after anodic oxidation at $20 \mathrm{~V}$ (Fig.2). When the voltage or solution temperature is up to a certain extent, there would be only collapsed structure remaining on the surface, which accounts for the phenomenon occurring at $30 \mathrm{~V}$ (Fig.3).

According to Wenzel theoretical model ${ }^{[13]}$, it can be seen, that if the surface is hydrophilic $\left(\theta<90^{\circ}\right)$, increasing of the surface roughness will decrease the surface contact angle, however, if the surface is hydrophobic $\left(\theta>90^{\circ}\right)$, increasing the surface roughness will increase the surface contact angle. In our work, the contact angle of original Ti surface is less than $90^{\circ}$ (Fig.5); after anodic oxidation for $5 \mathrm{~min}$, the hydrophilic surface is converted to be hydrophobic, however the prolongation of the oxidation time finally results in hydrophilicity again. Usually, the increasing of surface roughness will enhance the hydrophilicity. The inconsistency between surface roughness and hydrophilicity in initial period in our experiments (shown in Fig.4 and Fig.5) can be explained by surface energy ${ }^{[14]}$. At the beginning of anodic oxidation, the $\mathrm{F}^{-}$ions from electrolyte can react with $\mathrm{TiO}_{2}$ to generate fluorine compounds. Because the fluorine compounds have low surface energy ${ }^{[15]}$, sample surface is detected to be hydrophobic. With the prolongation of oxidation time, the influence of $\mathrm{F}^{-}$is 
weaker due to consuming, and then the formation of hydroxyl groups $(-\mathrm{OH})$ which have high surface energy determines the enhanced hydrophilicity of nanostructured surface $^{[16]}$.

\section{Conclusions}

1) Anodic oxidation can be applied to prepare different nanostructures on Ti surface, resulting in different surface roughnesses and hydrophilicities.

2) Roughness values of the anodized $\mathrm{Ti}$ surface increase with the increase of oxidation time, ranging from several dozen to several hundred nanometers, while the influence of voltage on surface roughness is not obvious.

3) The contact angle of water on the anodized Ti surface increases initially, then decreases, and finally remains stable with the prolonging of oxidation time.

\section{References}

1 Wang L, Lu W, Qin J et al. Mater Charact[J], 2010, 61: 535

2 Biswas A, Manna I, Chatterjee U K et al. Surf Eng[J], 2009, 25: 141

3 Kim J U, Jeong Y H, Choe H C. Thin Solid Films[J], 2011, 520: 793
4 Fathi M H, Salehi M, Saatchi A et al. Surf Eng[J], 2001, 17: 459

5 Qin R, Ding D Y, Ning C Q et al. Appl Surf Sci[J], 2011, 257: 6308

6 Zhao L, Liu L, Wu Z et al. Biomaterials[J], 2012, 33: 2629

7 Klein M O, Bijelic A, Ziebart T et al. Clin Implant Dent Relat $\operatorname{Res}[\mathrm{J}], 2013,15: 166$

8 Feschet-Chassota E, Raspal V, Sibaud Y et al. Thin Solid Films[J], 2011, 519: 2564

9 Macak J M, Tsuchiya H, Ghicov A et al. Curr Opin Solid State Mater Sci[J], 2007, 11: 3

10 Su Y T, Johansson C B, Jeong Y et al. Eng Phys[J], 2001, 23: 329

11 Cai Q Y, Paulose M, Varghese O K et al. Mater Res[J], 2005, 20: 230

12 Yasuda K, Schmuki P. Electrochim Acta[J], 2007, 52: 4053

13 Wenzel R N. J Phys Chem [J], 1949, 53: 1466

14 Nosonovsky M, Bhushan B. Adv Funct Mater[J], 2008, 18: 843

15 Barthwal S, Kim Y S, Lim S H. J Colloid Interf Sci[J], 2013, 400: 123

16 Kazuya N, Akira F. J Photoch Photobio C[J], 2012, 13: 169

\title{
阳极氧化处理对钛表面粗糙度和亲水性的影响
}

\author{
李宝娥 ${ }^{1}$, 李 军 ${ }^{1}$, 梁春永 ${ }^{1}$, 李海鹏 ${ }^{1}$, 郭立童 ${ }^{2}$, 刘世敏 ${ }^{3}$, 王洪水 ${ }^{1}$ \\ (1. 河北工业大学, 天津 300130) \\ (2. 中国矿业大学，江苏 徐州 221116) \\ (3. 天津商业大学, 天津 300134)
}

\begin{abstract}
摘 要: 通过阳极氧化处理技术在钛表面制备出具有不同粗粘度和亲水性的纳米表面。采用扫描电镜观察表面特征, 原子力显微镜检测 表面粗粘度, 接触角仪测量亲水性。实验结果表明, 表面形貌随着氧化电压和时间的改变有较大变化。在优化的电解液和氧化条件下, 可以在钛表面制备规则排列的纳米管阵列。粗糙度随着氧化时间的延长而增大，在几十到几百纳米之间变化，而氧化电压对粗糙度的影 响不大。表面亲水性随着氧化时间的延长先增加再降低。钛表面结构形貌、粗糙度与亲水性的变化可用阳极氧化过程中表面发生的反应 进行解释。
\end{abstract}

关键词: 钛; 阳极氧化; 粗糙度; 亲水性

作者简介: 李宝娥, 女, 1979 年生, 博士, 副教授, 河北工业大学材料科学与工程学院, 天津 300130, 电话: 022-26582149, E-mail: libaoe@hotmail.com 